\title{
ANALYSIS OF PHYSICAL FITNESS TESTS AND THE BODY COMPOSITION OF THE MILITARY PERSONNEL
}

\author{
Liana Pl̦avin̦a ${ }^{1}$, Silvija UmbrašKo ${ }^{2}$ \\ ${ }^{1}$ National Defence Academy of Latvia, Riga, Latvia \\ ${ }^{2}$ Riga Stradins University, Institute of Anatomy and Anthropology, Department \\ of Morphology, Riga, Latvia
}

\begin{abstract}
The Body composition is related to higher physical performance and a lower risk of health problems, it connects to external and internal factors. Military activitiesf are characterized with a high physical load and a psychological load, physical fitness and the body composition have an adverse effect on military performance. The primary purpose of the body composition and physical fitness is related to the selection of individuals the best suited to the demands of military service $[2,10]$. The proper body mass supports good health capacity $[11,13]$. The maintenance of body composition and appropriate physical fitness standards by the military personnel is affected by the intrinsic factors such as the individual's genetic factors, development history, social background, and extrinsic factors, environmental changes and institutional, systemic changes. The effects of the excess body mass are widespread, raise the variety of concerns relevant to the health and performance of the military personnel $[1,3,4,5]$. The diabetes mellitus, hyperlipidemia, hypertension and heart disease increased with the obesity $[6,7,9,12]$. The individuals with overweight have more medical complication than the individuals with the standard body mass. The higher body mass index was associated with higher morbidity and mortality [8]. We have classified individuals according to the age into subgroups and provided the evaluation of the body composition on the basis of the main anthropometric characteristics as well the analysis of the standard physical fitness tests results. The analysis of the average value of the body mass and the Body Mass Index have shown large individual changes inside the subgroups and between the subgroups. The assessment of the results of physical fitness tests is provided differentially according to the individual corresponding age subgroup. The analysis of the respondent data
\end{abstract}


reveals the overweight and obesity problem that became actual with the increasing the age of individuals. Physical fitness tests results have shown that the excellent physical fitness evaluation is received by about $33-44 \%$ of the military personnel that reflects a high unit of operational readiness.

Keywords: anthropometric characteristics; body composition; military personnel fitness

\section{INTRODUCTION}

The National Armed Forces like other militaries recognize that physical fitness is a key contribution to operational readiness. The primary purpose of the body composition and physical fitness is related to the selection of individuals the best suited to the demands of military service $[2,10]$. The proper body mass supports good health capacity $[11,13]$. The effects of excess body mass are widespread, raise the variety of concerns relevant to the health and performance of the military personnel $[1,3,4,5]$. The diabetes mellitus, hyperlipidemia, hypertension and heart disease increased with the obesity $[6,7,8,9,12]$. Since the foundation of NAF it was established that the military personnel should annually go through a physical fitness control programme. It includes standard physical tests: push-ups tests, sit-up tests and the cross country race (for a male $3,000 \mathrm{~m})$. Age distribution of the military personnel in the National Armed Forces is wide from eighteen to sixty years. Therefore the evaluation of physical preparedness and physical fitness on the basis of the standard physical tests result is differentiated. The basic requirement of physical fitness employability and deploy-ability are codified in the NAF. Administrative orders and directives define the minimum standard that the military personnel (in specific age group) are expected to meet. The military personnel who are unable to meet generic standards will likely be released from the Armed Forces. We provide the analysis of physical fitness data and anthropometric characteristics for the personnel from one military unit. Military environment requires high physical preparedness, therefore each person individually pays attention to the improvement of physical endurance weekly and annually and successfully passes the complex of standard physical tests.

\section{MATERIAL AND METHODS}

We assess the anthropometric measurement and the results of physical standard tests for 280 males aged from 18 years to 50 years. All the examined persons 
were classified according to age into subgroups: the 1st group includes the individuals in the age from 18 to 27 years; the $2^{\text {nd }}$ group is formed by the individuals in the age from 28 to 35 years; the $3^{\text {rd }}$ group consists of the individuals in the age from 36 to 40 years; the $4^{\text {th }}$ group contains the individuals in the age from 41 to 45 years; the $5^{\text {th }}$ group embrace data of the individuals in the age from 46 to 50 years. We provide the analysis of basic anthropometric measurements: the body mass, the body height. The Body Mass Index was calculated by dividing weight (kilograms) by the square of height (meters). We evaluate the results in the complex of standard physical tests: push-ups tests, sit-up tests and cross country race (for males $3,000 \mathrm{~m}$ ). The range of evaluation is from poor to excellent.

\section{RESULTS AND DISCUSSION}

We examined the military unit that contains the military personnel aged from 18 to 50 years. Despite of the wide age variation of respondents we pointed out that $77 \%$ of the military personnel in the unit are in the age from 18 to 35 years. The age distribution of the military personnel in the examined group is shown in Figure 1. We provide the assessment of the main anthropometric characteristics of the persons of the examined group. The analysis of the main body height of the military personnel revealed a small difference between the average data of height in the age subgroups (Figure 2). The growing process concludes to the age of 20-23 years and further changes of the height parameter are not found. The variation of the height of persons inside the age subgroup is from the minimal value $167 \mathrm{~cm}$ to the maximal value $200 \mathrm{~cm}$. The analysis of the body mass value reflects a large scale of variation in age subgroups of the examined personnel (Figure 3). For individuals in the age from 18 to 27 years the average value of the body mass is $83.6 \pm 1.3$, the minimal body mass value was $58 \mathrm{~kg}$, but the maximal body mass value $-115 \mathrm{~kg}$. The body mass value gradually increases with the age. More rapidly the body mass value increases from $85.8 \pm 1.4$ ( $2^{\text {nd }}$ subgroup) to $91.7 \pm 3.3$ ( $3^{\text {rd }}$ age subgroup) that is represented in Figure 3. We provide the analysis of the body mass index value inside of each age subgroup. The body mass average value in the age subgroups also consequently increases with the age from $24.6 \pm 0.3$ ( $1^{\text {st }}$ subgroup) to $29.0 \pm 2.6$ ( $5^{\text {th }}$ subgroup) that is represented on Figure 4 . The number of individuals that have the standard Body Mass Index value (norm) consequently diminishes with the age. In the $1^{\text {st }}$ subgroup that includes 18 to 27 years old young men, we have found $56.9 \%$ respondents with the standards value of the Body Mass Index. The number of persons with the standard Body Mass Index decreases 
to $39.2 \%$ in the next age subgroup that includes males in the age from 28 to 35 years. There are four times fewer (14.2\%) persons with the standards level of the Body Mass Index in the fifth age subgroup that includes individuals from 46 to 50 years compared with the first age subgroup (Figure 5).

The aging process is expressed with the changes of the body composition that was expressed with the increasing body mass and at the same time the elevation of the value of the Body Mass Index. Increasing of the body mass is one of the risk factor for medical problems such as muscular skeletal disorders and also cardiovascular diseases. The distribution of the Body Mass Index value expresses that the number of the individuals with overweight, when the value of the Body Mass Index was over 25.0 increases. The individuals with overweight form $27.7 \%$ in the age group that includes from 18 to 27 years. But the age subgroup for the individuals from 41 to 45 years had $66.7 \%$ of overweight persons in the subgroup. The number of the individuals with adiposity problem composes about $1 / 6$ of subgroup persons inside the $1^{\text {st }}$ age subgroup. There are $17.6 \%$ of militaries with the adiposity problem in the second age subgroup that includes 27 to 35 years old individuals. The number of individuals with such a problem increased with the age. In the fifth age subgroup there are $28.4 \%$ individuals with adiposity. It is important for the military personnel to pass annual physical fitness tests that is shown in Figure 6.

The assessment of the complex of the Standard physical tests (push-ups, situps and country cross race $(3,000 \mathrm{~m}$, for a male) was conducted by the sport instructors. The results were equated to points with a differential approach according to the age of the individual (in age subgroups). $33.0 \%$ to $43.1 \%$ of the military person show excellent results in the physical fitness test in each age subgroup. The number of individuals that get zero points in the physical fitness tests evaluation compose about 3.6 to $8.3 \%$ in each subgroup. The number of such individuals dramatically increases up to $21.3 \%$. in the age subgroup that includes 46 to 50 years old individuals. The high value of the body Mass and the Body Mass Index is related to lower physical performance and a higher risk of health problems that presume very soon the discharge of such individuals from the Armed Forces. 


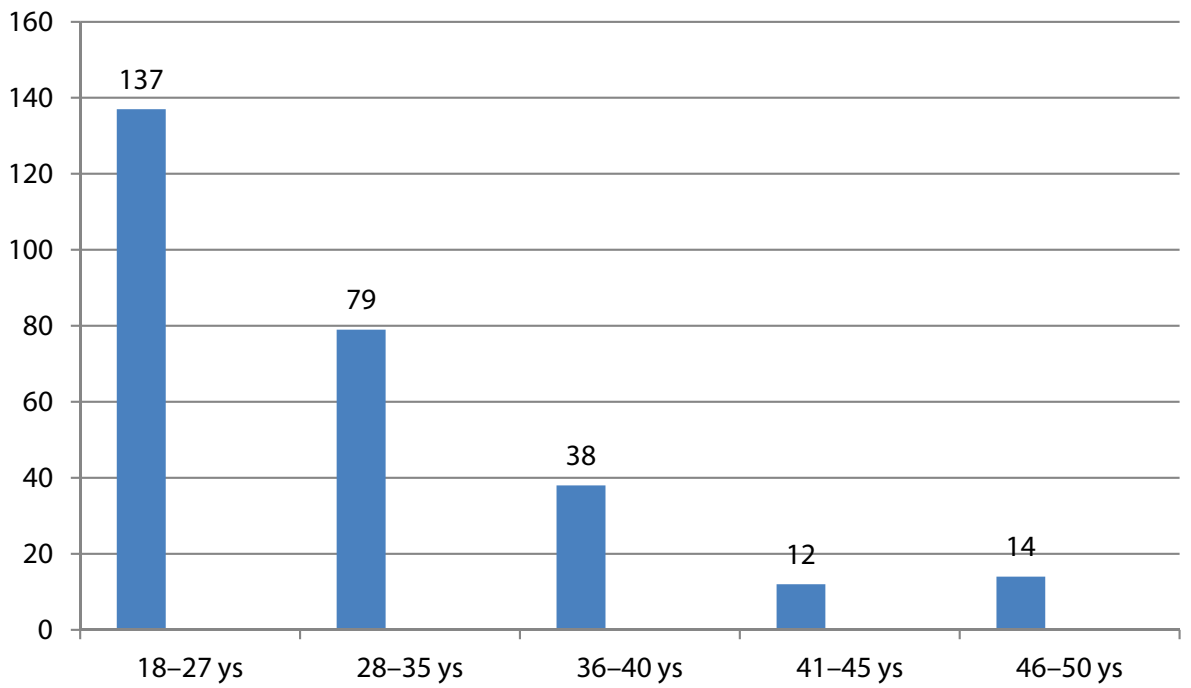

Figure 1. Age distribution of the military personnel in the examined group.

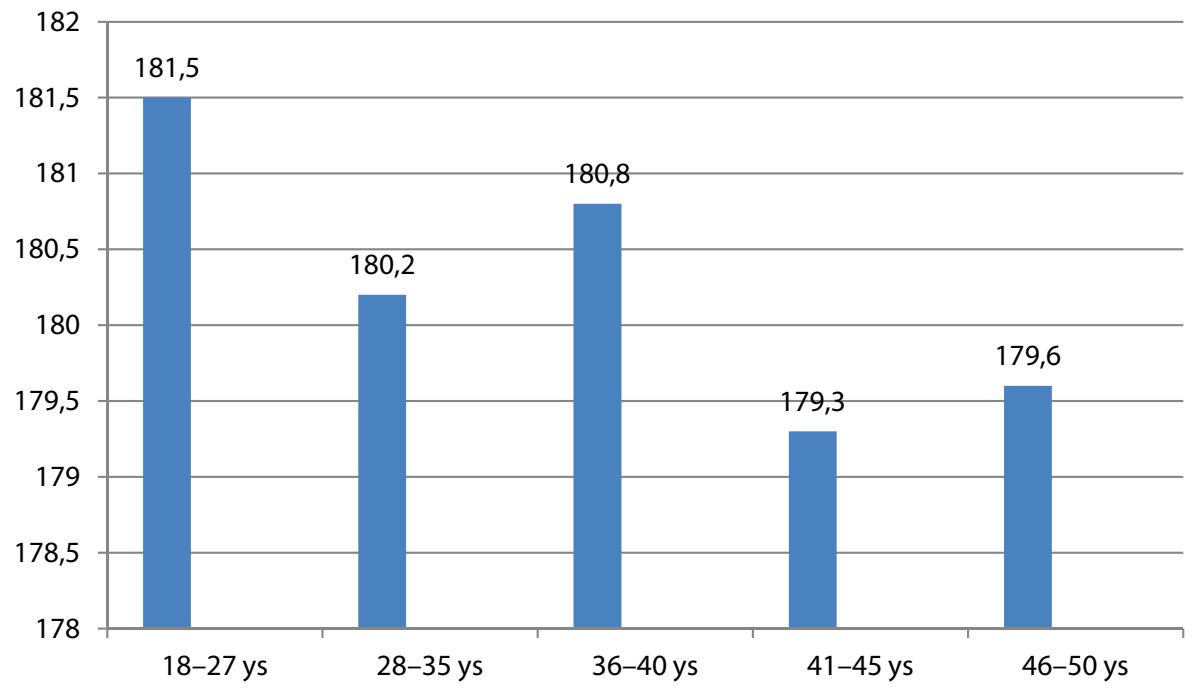

Figure 2. Height $(\mathrm{cm})$ distribution of the military personnel in the examined group in various age subgroups. 


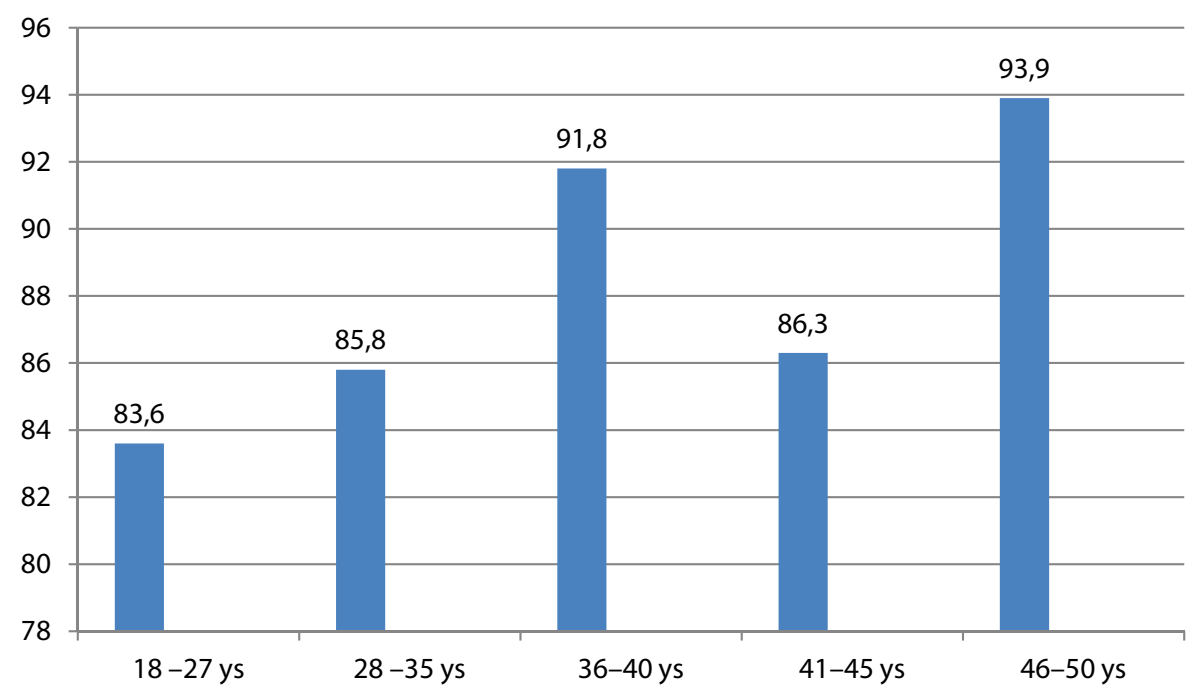

Figure 3. Body mass $(\mathrm{kg})$ distribution of the military personnel in the examined group in various age subgroups.

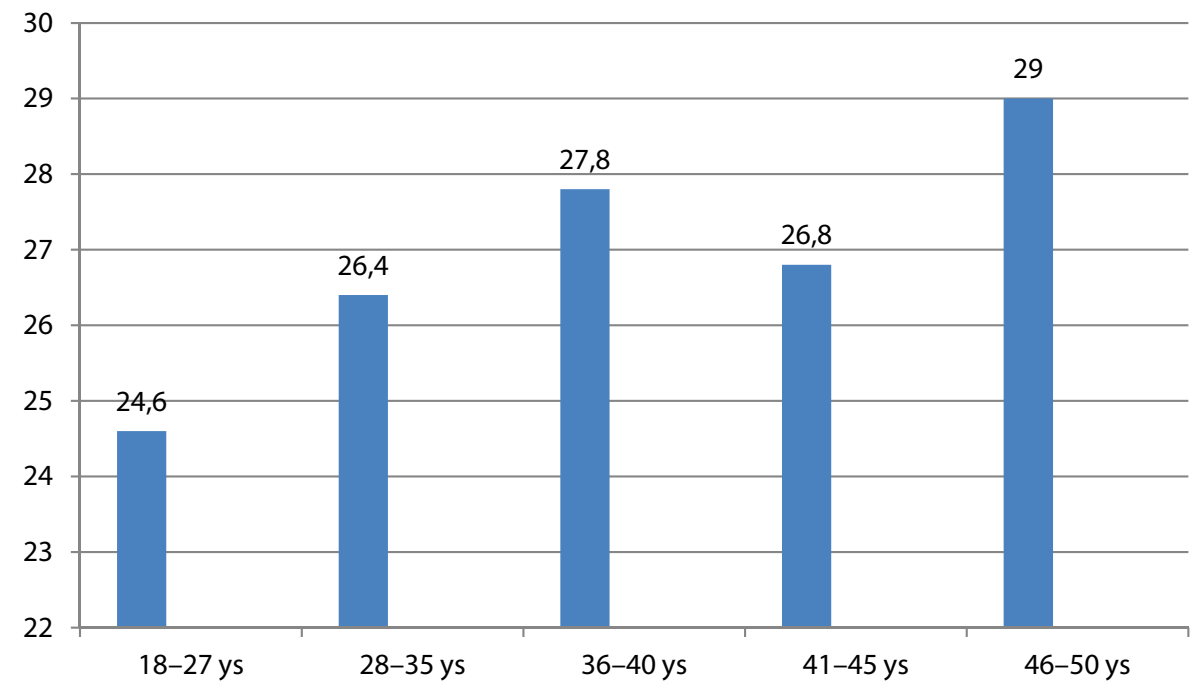

Figure 4. Average value of the Body Mass Index data distribution of the military personnel in the examined group in various age subgroups. 


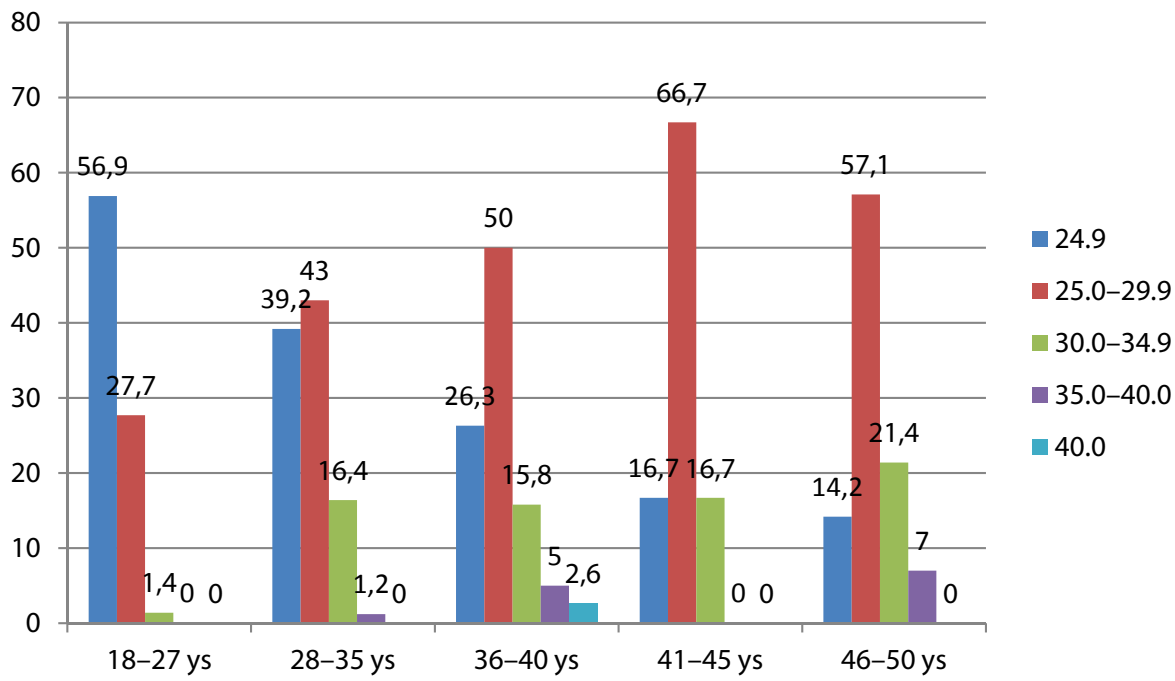

Figure 5. Body Mass Index value distribution of the military personnel in the examined group in various age subgroups.

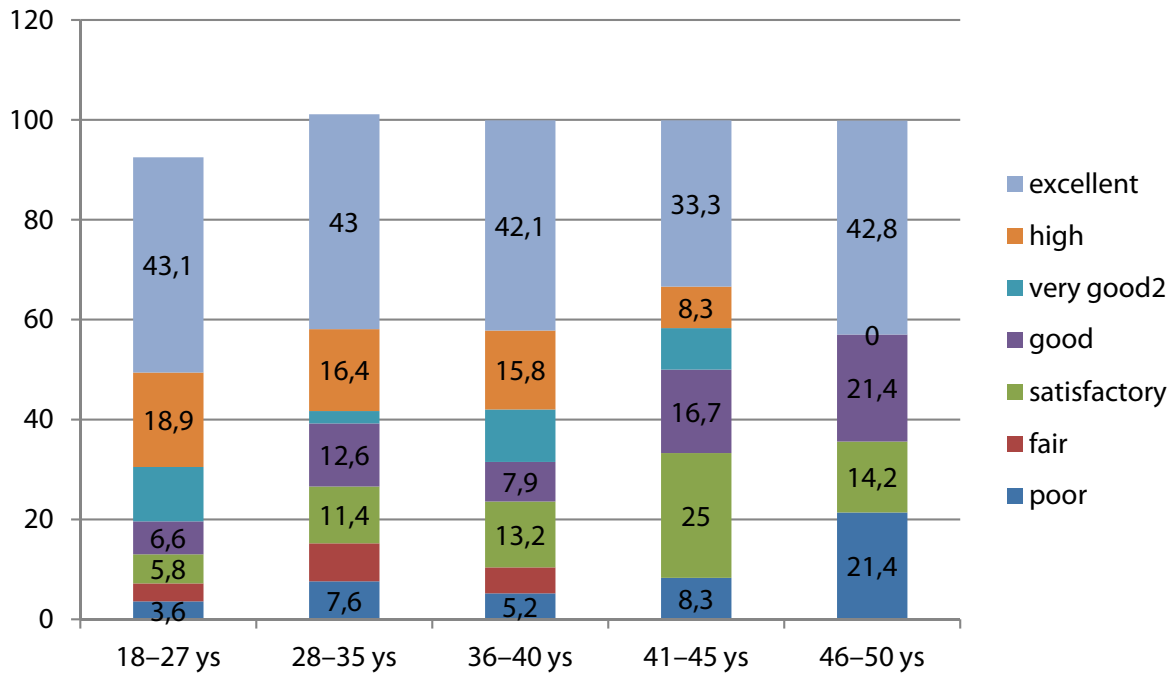

Figure 6. Results of complex physical tests for the military personnel in various age subgroups according to range. 


\section{CONCLUSION}

1. The military unit personnel has a wide range in aging dispersion from 18 to 50 years old men The $77 \%$ of unit personnel belong to the age interval from 18 to 35 years. Annually the military personnel pass the physical fitness tests. The assessment of the results of physical fitness tests is provided differentially according to the individual corresponding age subgroup. Physical fitness attests the results show that the excellent physical fitness evaluation is received by $33-44 \%$ of the military personnel that reflects high operational readiness of the unit.

2. The analysis of anthropometric characteristics has shown large changes of the body mass and the Body Mass Index. The body mass of the military in the age from 18 to 27 years in the case of $77.3 \%$ of respondents is included in the interval between 71 to 90 kilograms. The body mass value gradually increases with the age from $83.6 \pm 1.3 \mathrm{~kg}$ in the first age subgroup (18 to 27 years) to $93.9 \pm 3.8 \mathrm{~kg}$ in the fifth subgroup (from 46 to 50 years). Increasing of the body mass value was reflected also in the increasing the Body Mass Index that also increased from $24.6 \pm 0.3$ in the first age subgroup (18 to 27 years) to $29.1 \pm 2.6$ and the fifth age subgroup (46 to 50 years).

3. The analysis reveals the overweight and obesity problem that became actual with the increasing of the age of individuals. Overweight is fixed for $27.7 \%$ of young 18 to 27 years old men( first subgroup) and the obesity - for $1.4 \%$ of respondents of this age subgroup. Half of the respondents (50\%) of the third age subgroup in the age from 36 to 46 years were with fixed overweight, the adiposity problem is found for $23.4 \%$ of the respondents of this group. Adiposity is a high risk for medical problems such as cardiovascular diseases, musculoskeletal pathologies and metabolic diseases. Overweight and obesity is a reason why the results in the physical fitness test are poor and fair for $10.4 \%$ of the respondents in that group.

\section{REFERENCES}

1. Feuerstein M., Berkowitz S., Peck C.A. Jr. (1997). Musculoskeletal-Related Disability in US Army Personnel: Prevalence, Gender, and Military Occupational Specialties Med J. of Occupational \& Environmental Medicine, 39(1), 68-78.

2. Gallagher D., Heymsfield S.B., Heo M., Jebb S.A., Murgatroyd P.R., Sakamoto Y. (2000). Healthy percentage body fat ranges: an approach for developing guidelines based on body mass index. Am J Clin Nutr, 72(3), 694-701. 
3. Heir T., Eide G. (1996). Age, body composition, aerobic fitness and health condition as risk factors for musculoskeletal injuries in conscripts. Scand. J, Med Sci Sports, 6(4), 222-7.

4. Parkkari J., Taanila H., Suni J., Mattila V.M., Ohrankämmen O., Vuorinen P., Kannus P., Pihlajamaki H. (2011). Neuromuscular training with injury prevention counselling to decrease the risk of acute musculoskeletal injury in young men during military service:a population-based randomised study. BMC Medicine, 9, 35. (http://www.biomedcentral.com/1741-7051/8/35).

5. Taanila H., Suni J., Pihlajamäki H., Mattila V.M, Ohrankämmen O., Vuorinen P., Parkkari J. (2010). Aetiology and risk factors of musculoskeletal disorders in physically active conscripts: a follow-up study in Finnish Defence Forces. BMC Musculoskelet Disorders, 11, 146. ( http://www.biomecentrral. com/1741-7-51/9/35).

6. Lystrup R., Gordon F., Ward M., Hall J., Stephens M. (2015). Exploring the Impact of a Pedometer on Body Composition and Physical Fitness in a Cohort of U.S. Military Medical Students: A Pilot Study. Military Medicine, 180(1), 23.

7. Nogueira E.C., Porto L.G., Nogueira R.M., Martins W.R., Fonseca R.M., Lunardi C.C., de Oliveira R.J. (2016). Body composition is strongly associated with cardiorespiratory fitness in a large Brazilian military firefighter cohort: the Brazilian firefighters study. Journal of Strength \& Conditioning Research, 30(1), 33-38.

8. Mikkola I., Keinänen-Kiukaanniemi S., Jokelainen J., Peitso A., Härkönen P., Timonen M., Ikäheimo T. (2012). Aerobic performance and body composition changes during military service. Scandinavian Journal of Primary Health Care, 30(2), 95-100.

9. McLaughlin R., Wittert G. (2009). The obesity epidemic: implications for recruitment and retention of defence force personnel. Obesity Reviews, 10(6), 693-699.

10. Friedl K.E. (2012). Body Composition and Military Performance - Many Things to Many People. Journal of Strength \& Conditioning Research, 26 (Supplement 2), S87-S100.

11. Aandstad A., Hageberg R., Holme I.M., Anderssen S.A. (2014). Anthropometrics, body composition, and aerobic fitness in Norwegian home guard personnel. J Strength Cond Res, 28(11), 3206-14.

12. Singh R., Prakash M., Dubey R., Roy K., Kotwal A., Mahen A. (2013). Body composition parameters as correlates of coronary artery disease. Indian J Med Res, 138(6), 1016-9.

13. Kennedy-Armbruster C., Evans E.M., Sexauer L., Peterson J., Wyatt W. (2013). Association among functional-movement ability, fatigue, sedentary time, and fitness in 40 years and older active duty military personnel. Mil Med, 178(12), 1358-64. 
Address for correspondence:

Liana Pl̦aviña

National Defence Academy of Latvia

Riga, Latvia

LV-1014, Ezermalas str.8

Tel. +371 29208611

Fax: +371) 67076888

Silvija Umbraško

Riga Stradins University

Institute of Anatomy and Anthropology, Department of Morphology

Riga, Latvia

LV-1010, Kronvalda bulv.9

Tel. +371 26444364 